\title{
Gastritis and Peptic Ulcer Diseases in Dogs: A Review
}

\author{
Pankaj Kumar Patel ${ }^{1}$, Sawita Kumari Patel ${ }^{2}$, S.K. Dixit ${ }^{\text {* }}$ and R.S. Rathore ${ }^{2}$ \\ ${ }^{1}$ Division of Medicine, ${ }^{2}$ Division of Veterinary Public Health, ICAR-Indian Veterinary \\ Research Institute, Izatnagar, UP-243122, India
}

*Corresponding author

\section{A B S T R A C T}

\begin{tabular}{l} 
K e y w o r d s \\
$\begin{array}{l}\text { Antioxidant therapy, } \\
\text { Gastric mucosa, } \\
\text { Helicobacter pylori, } \\
\text { Oxidative stress, Triple } \\
\text { therapy }\end{array}$ \\
\hline Article Info \\
\hline $\begin{array}{l}\text { Accepted: } \\
\text { 20 February } 2018 \\
\text { Available Online: } \\
\text { 10 March } 2018\end{array}$ \\
\hline
\end{tabular}

\section{Introduction}

Gastric diseases of dogs are usually gastric mucosal inflammation, ulceration, obstruction or neoplasia. Gastritis is the inflammation of gastric mucosa and normally visualized by vomiting. Categorization and gradation of canine gastritis are based on the nature of the predominant cellular infiltrate and the presence of architectural abnormalities (Day et al., 2008). Acute gastritis is clinically characterized by the sudden onset of vomiting (Ettinger and Feldman, 2005) whereas chronic gastritis is clinically defined as intermittent vomiting with duration of more than 1-2 weeks (Day et al., 2008). It occasionally coupled with the loss of body weight, inappetence, and spells of abdominal pain. In most patients the cause is secondary from the history, such as dietary indiscretion; the diagnosis is rarely confirmed by biopsy, and treatment is symptomatic and supportive. If the hyperplastic polyp (Gencosmanoglu et al., 2003) or foreign body (Papazoglou et al., 2003) obstructs the pyloric region of stomach results onset of acute clinical signs, however if foreign object stays on the body of the stomach may lead to mucosal injury and acute gastritis (Amorim et al., 2016). Fungal infections and spirochetes also lead to gastritis (Helman et al., 1999). Chronic gastritis is defined as the presence of 
intermittent vomiting for more than 1-2 weeks (Dowdle et al., 2003).

The peptic ulcer is the imperfection in the mucosal barrier that continues to the muscularis mucosa of the stomach (Stanton and Bright, 1989). The most common clinical symptoms are sudden onset of acute vomiting with or without blood, dehydration, anorexia, weight loss and depression. Peptic ulcer most commonly leads to the condition of GI hemorrhage.

In dogs, non-steroidal anti-inflammatory drugs (NSAIDs), hepatic and renal disease are the most common predisposing factor for the formation of peptic ulceration that leads to anorexia, haematemesis, melena, dehydration, anaemia and abdominal pain. Chronic ulcers have varying size and are larger than normal (Brown et al., 2007).

Chronic gastric ulcers and local ulcerative neoplastic lesions are macroscopically relatively similar; they can be differentiated through histopathological examination (Stanton and Bright, 1989). Based on histological examination (relative control of the reparative processes and the severity of ulceration), the gastric ulcers are classified as acute or chronic.

Microscopically, subacute to chronic ulcers have granulation tissue of uneven thickness and ripeness, infiltrated by a mixed inflammatory cell population and covered by a thin layer of necrotic debris at the bottom and boundaries along with superficial regenerative epithelial hyperplasia (Brown et al., 2007).

\section{Review of literature}

\section{Incidences}

Gastric disorders are common finding which 35 percent cases look into chronic vomiting and 26-48 percent of dogs are asymptomatically affected (Wiinberg et al., 2005). Although there is a high prevalence of gastritis in dogs, an underlying cause is rarely identified. In Madras veterinary college teaching hospital (two semesters), out of the total reported canine patients, $16.8 \%$ dogs were suffering from gastrointestinal disorders and $0.19 \%$ was reported from duodenal ulcers (Saravanan et al., 2012). In Mekelle veterinary clinic Ethiopia, out of the total 109 reported canine patients, $36(33.0 \%)$ were suffered from gastrointestinal tract disorders and $15(41.7 \%)$ dogs have been shown vomiting (Atsbaha et al., 2014). It is the condition which can be diagnosed on the basis of clinical signs, laboratory findings, and results of imaging techniques such as radiography, ultrasonography, and endoscopy. The most important diagnostic technique for gastritis is the endoscopic examination. In the case of gastritis mostly Helicobacter Spp. organisms are isolated from gastric mucosal biopsies of dogs (Wiinberg et al., 2005). Endoscopic reports show that the chances of formation of gastric mucosa ulcer are 48.5 percent in canines (Parrah et al., 2013).

\section{Classification of gastritis}

Gastritis in dogs classified into acute or chronic which caused by multiple etiological agencies such as dietary carelessness, ingestion of coarse foreign bodies, plant materials, irritant chemicals, drugs (NSAIDs, glucocorticoids), viral diseases (e.g. canine parvovirus, canine distemper) and bacterial infections e.g. Helicobacter spp.). Metabolic disorders frequently present with haematemesis, melena, concurrent diarrhoea and other signs of systemic illness. Acute gastritis is the inflammation of the mucosal layer of the stomach which is characterised by sudden onset of vomiting and suspected to be related to gastric mucosal injury or inflammation (Amorim et al., 2016). Only some reports showed the role of an infectious 
agent in acute gastritis (Brown et al., 2007; Simpson, 2013). Chronic gastritis classify based on nature of the leading cellular infiltrates (eosinophilic, lymphoplasmacytic, granulomatous or lymphoid follicular), the presence of architectural abnormalities (atrophy, hypertrophy, fibrosis, oedema, ulceration or metaplasia), severity (mild, moderate or severe) (Wilcock, 2013). It can also be subclassified on the basis of distinct histological classification, Chronic superficial gastritis (CSG) is the most common form of chronic gastritis that no have understandable changes in mucosal thickening always associated with excessive but uneven inflammatory components (Plasma cells, neutrophils, lymphocytes) infiltrate and fibrosis of mucosa and submucosa. Clinical importance of chronic atrophic gastritis (CAG) has occasionally reported (Simpson, 2013) which is characterised by diffuse lesions in fundus and body of the stomach and reduced mucosal layer thickening as well as hypochlorhydria, achlorhydria and proportionally increased of the number of mucus-producing cells within the gland (Wilcock, 2013).

Loss of gastric glands due to atrophy of the gastric mucosa and combines with mononuclear infiltration, glandular atrophy, regenerative glandular nesting and mucosal fibrosis and loss of feedback mechanism leads increased serum gastrin level causes gastric ulceration (Ditchfield et al., 1960; Rugge et al., 2002; Amorim et al., 2016). Lymphoplasmacytic gastritis (LPG) with or without coupled with hyperplasia of lymphoid follicles, infiltration of lymphocytes and other inflammatory cells, including Russell bodies into the lamina propria layer of the stomach and sometimes it may be associated with Helicobacter spp. infection (Maxie, 2007; Amorim et al., 2016). Eosinophilic gastritis (EG) rarely reported by widespread Alimentary tract hypersensitivity reaction (eosinophilic gastroenteritis). Diffuse form of EG has Scirrhous inflammatory thickening on the gastric wall that resembles with gastric neoplasia (Hayden and Fleischman, 1977; Neiger, 2008; Lidbury et al., 2009). Genetic predisposition and diet are noticed for pathogenesis (Sattasathuchana and Steiner, 2014) but some factors like gastric parasitic infestation by Physaloptera spp. (Neiger, 2008), Gnathostoma spp. (McCarthy et al., 2000), Heterobilharzia americana (Rodriguez et al., 2014) and mastocytoma along with infiltration of eosinophils (Ozaki et al., 2002), lesions are rarely observed in Toxocara canis infestation (Chira et al., 2005). Focal type chronic hypertrophy occurs as a result of chronic administration of Aspirin. Focal cystic hypertrophic gastropathy is characterised by histopathologically elongated and complexed mucous glands with the recurrent formation of the mucosal cyst. Hypertrophic glandular gastritis is frequently associated with a diffused immune proliferative enteropathy on basenji dogs and this condition also occurs in many dogs due to Hypergastrinemia (Breitschwerdt, 1992). Chronic Giant hypertrophic gastritis (GHG) is rarely found in dogs and characterized by marked thickening on the gastric wall and mucosal hypertrophy gives a cerebriform look to the rugal folds which protrude into the gastric lumen (Vaughn et al., 2014). Chronic hypertrophic pyloric hypertrophy is hypertrophy of mucosal layer of the antropyloric stomach. Lesions are focal/multifocal, polyploidy thickening / regionally generalised rugal enlargement and these lesions are lead to gastric outlet obstruction (Elwood et al., 2010).

\section{Patho-physiology of gastritis and peptic ulcer disease}

The gastric mucosal layer acts as a useful protective wall against acidity, bacteria, detergents and alteration in luminal 
temperature. The first line of defence of gastric wall is gastric secretion which contains acid, mucus, bicarbonate and antibacterial substances. Epithelial layer on the wall of the gastric glands and gastric mucosal layer prevents from reverse-diffusion of acids and is rapidly repaired by restoration after injury. The quick response showed through gastric mucosa against stimulation of neurohormonal and inflammatory signals to the gastric microvasculature by increasing blood supply for maintenance of gastric mucosal integrity, removal of harmful substances, and restoration of the gastric epithelial layer (Abdel-Salam et al., 2001; Kawano and Tsuji, 2000). Stimulation to the gastric wall by foreign materials, chemical injury, ischemia, infection, or antigens leads to release of inflammatory components and vasoactive substances from neutrophils, mast cells, platelets, endothelial cells and neurons (Wallace and Ma, 2001). Several proinflammatory cytokines are released as a response to the pathogenesis of peptic ulcer, like interleukin (IL)- Ib, IL-2, IL-6, IL-8 and tumour necrosis factor (TNF)- $\alpha$. IL-I, lead to reduce the severity of the gastroduodenal injury and increase the resistance to gastric injury (Wallace et al., 1990). These inflammatory components stimulate acid secretion and mucosal breakage increases the permeability of epithelial layer and altered blood flow that continues increase the risk of gastritis, gastric erosion, ulceration, hypoxia, haemorrhage, oedema and necrosis (Jacobson, 1992). Granuloma formation of gastric mucosa is the end result of a response to endogenous substances and foreign objects, such as sewing needles and infectious diseases (Pratt et al., 2014). Transient ulceration commonly noticed due to direct damage of gastric wall and mucosal barrier or generally ingestion of a wide range of foreign materials like coarse foods, chemicals, plants materials, clothes etc. Gastric ulceration is caused by the multi-etiological agent that includes gastric mucosal damage by physical agent, alterations in the chemical structure and its renovate process (Parrah et al., 2013). Mechanical scratch ulceration is generally superficial and short-lived and superficial lamina propria covered by fibrin, mucus and scattered neutrophils (Wilcock, 2013). Secretion of hydrochloric acid that creates acidity catalyzes pepsinogen to the active proteolytic enzyme pepsin (Chu and Schubert, 2012). Hamper integrity and protective mechanism disturbance in mucosal layer initially, increase rate of reverse diffusion of gastric acid and pepsin lead to GI inflammation and haemorrhages than inflammatory components (e.g. endothelial cells, neutrophils and mast cells) become activated and release inflammatory mediators (e.g. histamine, leukotrienes, plateletactivating factor, proteolytic enzymes, and free radicals) (Henderson and Webster, 2006). Histamine promotes gastric acid secretion; whereas another mediator promotes vascular changes (e.g. vasodilation, vasoconstriction, increased capillary permeability) lead to oedema and translocation of inflammatory cells that plugged the capillary lumen, intensify initial gastric mucosal injury by dropping blood flow, ischemia, disturbed epithelial cell layer restoration, and reduced secretion of mucus and PG-E (Sorjonen et al., 1983; Guilford et al., 1996). Gastric ulcers also have been reported in dogs, having hepatic disease, renal disease, Addison's disease; shock (Parrah et al., 2013). Dogs having the severe head injury, numerous trauma, cerebral injuries and diseases of spinal cord leads to Gastroduodenal ulceration (Neiger and Simpson, 2000; Dowdle et al., 2003).

\section{Etiopathogenesis of gastritis and peptic ulcer diseases}

Gastric foreign bodies are the most common cause of gastric disorders in younger dogs 
(Sullivan and Yool, 1998). Ingestion of exogenous toxins like a household, cleaning chemical, lead and various plants may directly harm to the gastric mucosal barrier (Sass, 1970). In three dogs experimentally administration of phenol (total dose of 2430 $\mathrm{mg}$ of phenol) leads severe oral and gastric ulceration (Gieger et al., 2000). When orally lead salt mixture (Chloride Br, Sulfate, 1:1:2) give orally in nine dogs at diverse doses (range $5-60 \mathrm{mg} / \mathrm{kg}$ body weight/day) for 14 152 days gastric ulceration is induced (Hamir et al.,1983). Systemic hypovolemia leads to decrease blood flow to gastric mucosal layer, there is the loss of the tolerable effects of glucocorticoids in mucosal defense mechanism and major electrolyte abnormalities are leads to gastritis (Henderson and Webster, 2006). Dogs with kidney failure have infrequently shown gastric necrosis and ulceration (Peters et al., 2005). Gastric ulcers due to stress less commonly noticed in dogs, regular and severe exercise have a higher risk for occurrence of gastric ulcers in dogs and during sled races mostly gastric disease has known as a causative factor of sudden death in the dog (Chatelain et al., 2014). The diet containing a high amount of fat causes delayed gastric emptying and hyperacidity in the stomach, which in alone or associated with the physiological reaction of stress (increasing the level of serum cortisol level), may influence to GI ulceration in animals (Davis et al., 2003).

The aspirin-induced gastric disorders maximally reported in antropyloric area administrated dogs (Reimer et al., 1999; Ulutas et al., 2006). Administrations of a diversity of NSAID drugs piroxicam including, aspirin, ibuprofen (Godshalk et al., 1992; Lanza et al., 2009) naproxen and flunixin meglumine or ibuprofen (Godshalk $e t$ al., 1992; Dow et al., 1990), steroidal antiinflammatory drugs used for treatment of spinal and vertebral diseases (Neiger, 2000) are also reported as cause of gastric ulceration (Gralnek et al., 2008). Some drug has been damaged in the gastric mucosal layer of dogs includes glucocorticoids (Valin and Allard, 2012) and various NSAIDs (Mathews et al., 1996). Selective inhibitors of Cyclooxygenase (COX)-2 (e.g. carprofen, etodolac, deracoxib, meloxicam) are used to reducing the ulcerogenic consequence of NSAIDs in the GI tract. Even if they reduce the hazard but they do not fully remove it and in many dogs have reported that formation of gastric ulceration subsequently the given of these safer NSAIDs (Enberg et al., 2006). The NSAIDs inhibits the enzyme COX which is involved in the prostaglandin synthesis, and inhibit the synthesis of prostacyclin and prostaglandin E, resulting in the loss of the gastric protective mechanism (Enberg et al., 2006). If any change on the expression of GKN gene leads to the deficiency of GKN1 \& GKN2, results have been reported as gastric inflammation, non-steroidal antiinflammatory (NSAID) induced mucosal injury and the development of neoplasia of gastric mucosa (Martin et al., 2008; Nardone et al., 2008). Another factor concerned with the pathogenesis of NSAID-induced gastric disorder is peroxidation of lipids of cell membranes and damage to the cellular proteins by the formation of oxidative free radicals and proteases from activated neutrophils (Biswas et al., 2003). NSAIDs acts on mitochondria and uncoupling effect on oxidative phosphorylation, disperse the mitochondrial transmembrane potential and induce mitochondrial permeability transition pore (Yoshida et al., 1992; Tomoda et al., 1994; Mahmud et al., 1996; Mingatto et al., 2000; Davies et al., 2000; Ulutas et al., 2006) leading to the release of cytochrome c from mitochondrial intermembranous space into cytosol. liberated cytochrome c generates reactive oxygen species (ROS) like hydrogen peroxide, thus activation of caspase 9 and caspase 3 pathway and peroxidation of 
cellular lipid membrane all resulting into cellular apoptosis (Murphy et al., 2000).

Corticosteroid predisposes the GI tract to damage by diminishing mucus production, changing the biochemical composition of mucus, declining restoration of epithelial cell layer and intensifying acid production (Sorjonen et al., 1983). It has been reported that administration of prednisolone after 1 or 2 weeks of peptic ulcer formation leads to decreased collagen-containing tissue in the ulcer base and delayed healing (Luo et al., 2004). Dexamethasone has been shown inhibitory effects of angiogenesis at the ulcer margins and baseline. Administration of corticosteroids along with NSAIDs leads to the formation of gastric mucosal lesions (Boston et al., 2003). Some studies had been shown that support the theory that corticosteroids alone lead to GI mucosal injury and hemorrhage (Rohrer et al., 1999).

The hepatic disease leads to portal hypertension which causes distorted gastric blood flow, delayed epithelial turnover, gastric hyperacidity, and elevated serum bile acid concentration stimulate to secretion of Gastrin-17, results in apoptosis of gastric epithelial cells (Henderson and Webster, 2006). Animals with mastocytosis may have numerous all over gastric ulcers (Stanton and Bright, 1989; Ozaki et al., 2002). The mast cell tumor produces and releases histamine, which binds to $\mathrm{H} 2$ receptors on gastric parietal cells, gives a powerful stimulant to acid secretion. In humans, peptic ulcer formation as a result of excessive gastrin production and hyperacidity caused by a gastrinoma is known as the Zollinger Ellison syndrome. This is a condition often characterized by the triad of hypergastrinemia, hypertrophic or CAG and GI ulceration. Few cases of a canine homolog of Zollinger Ellison syndrome associated with gastric ulcer formation are reported (Gal et al., 2011). Gastrin directly stimulates to hydrochloric acid secretion from the parietal cells, as well as indirectly stimulating acid production by releasing histamine from fundic enterochromaffin-like cells in response to compromising the protective mechanisms and reducing the epithelial cell turnover of the gastric mucosa (Hughes, 2006). Gross and histological appearances of gastric erosions and ulcers are well documented, erosions involve only surface epithelium with a minimal inflammatory response but ulcers can extend into the muscularis mucosae (Sullivan and Yool, 1998). The chronic liver disease leads to ischemia in GI mucosa that causes portal hypertension and thrombus formation into the gastric vessels (Stanton and Bright, 1989). The renal system has been involved in the elimination of at least $40 \%$ circulating Gastrin-17, with up to 40 percent of circulating Gastrin-17. Hence, in renal disease hampered to clearance of Gastrin-17 lead to hypergastrinemia which induced gastric acid production. It is the principal factor for vomiting and pathogenesis of gastric ulcer formation in renal disease (Schulman and Krawiec, 2000; Peters et al., 2005). Renal failure leading to progressive uremia and urea diffuses from interstitial fluids to stomach, results in damage to epithelial cell layer of gastric wall (Polzin and Osborne, 1995; Guilford and Strombeck, 1996).

The chief gastric pathogenic Helicobacter spp. in dogs are H. felis, H.bizzozeronii and $H$. heilmanniisensustricto (s.s.), while $H$. salomonis is least reported and the prevalence of $H$. cynogastricus and $H$. baculiformis has not yet been studied (Amorim et al., 2016). However, $H$. pylori have been rarely identified in the canine stomach (Chung et al., 2014). There is also evidence of mixed infections of different species (Ekman et al., 2013). Helicobacter spp. populations are mostly found in the fundus and body of the stomach (Anacleto et al., 2011). Gastrokines 
(GKNs) are bioactive molecules that contain BRICHOS domain and secreted from a specific cell of gastric mucosa (Menheniott et al., 2013). GKN1 connected with decreasing the formation of colonies and proliferation by an atypical glandular cell of gastric mucosa and reducing of cellular viability, proliferation, and colony (Yoon et al., 2013). GKNs and trefoil factors (TFFs) both are together lead to enhance cellular differentiation, cytoprotective role and working on NF- $\kappa \beta$ signalling pathways that result anti-inflammatory effects, therefore it promotes restoration of gastric epithelial cells (Rippa et al., 2011). If any change on the expression of GKN gene cause deficiency of GKN1 \& GKN2, results from gastric inflammation, non-steroidal antiinflammatory (NSAID) induced mucosal injury and the development of neoplasia of gastric mucosa (Martin et al., 2008; Nardone et al., 2008).

Gastric disease caused by $H$. pylori suppress to GKNs gene expression by methylation of trefoil factor 2 (Peterson et al., 2010), lead to Gkn1 and Gkn2 deficiency (Menheniott et al., 2013). Progressive loss of expression GKN gene lead to progression of different phases of disease development, started from chronic gastritis to gastric mucosal atrophy followed by a neoplasm of intestine due to complete loss of GKN gene expression (Sharman et al., 2017; Menheniott et al., 2013). Electron microscopic examination of gastric mucosa showed spiral-shaped organisms in the lumen of stomach and canaliculi of parietal cells (Lee et al., 1992). Pathogenic viral infections in dogs include parvovirus; distemper virus, rotavirus, and coronavirus rarely causes gastritis with intestinal or systemic involvement being most responsible for patient morbidity and mortality.

Parasitic infestation is least commonly reported. The larvae of Spirocerca lupi pierce the gastric mucosal barrier than severe mixed inflammatory/neoplastic-like reaction and forms nodular foci, these are generally known as granulomas (van der Merwe et al., 2008). The initial stage of inflammation, larvae encircled by loose connective tissue that are extremely vascularised and containing fibrinrich fluid, neutrophils, and foci of necrosis. Later stage, these connective tissues are composed mostly of actively dividing fibroblasts which like embryonic appearance, sometimes similar to sarcoma (Bailey, 1963). In Gnathostoma spinigerum infestation, adult parasite formed solid nodules in the gastric submucosa and they stick out into the lumen and parasite eggs trapped by connective tissue lead to the formation of center portion granuloma (Maleewong et al., 1992). The Hetero bilharzia mericanais trematode parasite leads to gastric granulomatous inflammation with circumscribing trapped eggs (Rodriguez et al., 2014). Gastric nematode infestation by Ollulanus tricuspis, which was commonly observed in cats (Cecchi et al., 2006) also has been reported in dogs with the sign of chronic vomiting and granulomatous gastritis (Kato et al., 2015). Nematodes, Physaloptera rara, and Physaloptera canis, an uncommon source of gastric ulceration related to chronic vomiting (Burrows, 1983). These parasites are free moving in lumen cause a minimal inflammatory reaction, but mostly they attached with the gastric mucosa lead to inflammation due to the formation of numerous minute hemorrhages (Clark, 1990). Gastric phycomycosis characterized by minute non-specific changes to thickening mucosal folds of gastric wall with outlet hindrance. Granulomatous lesions have typical nodular, circumscribed collections of macrophages along with uneven lymphocytes, eosinophils, multinucleated giant cells, and neutrophils, with or without central necrosis and a peripheral lymphoid cuff (Ectors et al., 1993). Histoplasmosis caused by the fungus 
Histoplasma capsulatum infected by spores via inhalation or ingestion route. These spores are phagocytized by macrophages and dispersed through the bloodstream or lymphatic channel to the organ systems and formation of subclinical or clinical granulomatous condition amongst other organs including the GI tract (LinBlache et al., 2011). In young aged, large-breed, male dogs Pythiuminsidiosum may produce pyogenic granulomas in mucosa and submucosa of stomach and different places of the GI tract (Grooters and Gee, 2002). Cryptococcus neoformans cause granulomatous gastritis mimicking carcinoma which is a factor of gastric outlet obstruction (Van der Gaag et al., 1991).

Different cellular defense mechanisms involve for protection against the free radical damage (Lewin et al., 1997). Enzymes (e.g. catalase, glutathione peroxidase complex and superoxide dismutase) and transition-metal binding proteins (e.g. transferrin, ferritin, and ceruloplasmin) production and action of free radicals. Scavengers (e.g. albumin, bilirubin, ascorbic acid, urates, and thiols, or liposoluble, such as vitamin E and coenzyme Q10) stop and discontinue radical chain by increase peroxidation chain of lipid molecules by a react and neutralize free radicals and convert them into more stable molecules. The peroxidized fatty acids are removed by specific phospholipases, making possible the re-acylation of the damaged molecule by an acetyl-CoA and the respective enzyme lead reconstitution of normal structures. The overproduction of ROS leads to the imbalance between oxidants and antioxidants at cellular as well as systemic level. Reactive oxygen species (ROS) are major molecules of oxidative stress in exceeds the threshold level which is generated as primary part of metabolism that lead to trigger progressive destruction of polyunsaturated fatty acids (PUFA) and membrane destruction
(Halliwell, 1990). In acute events of inflammation free radicals may play a major role in gastric mucosal barrier dysfunction. In humans oxidative stress occurs during exercise leads to decrease gastric and mesenteric blood flow (Qamar et al., 1987; Mastaloudis et al., 1994; Hinchcliff et al., 2000; Otte et al., 2001; Radak et al., 2003) along with mitochondrial electron transport chain inefficiency during respiration leading reperfusion injury mediated by ROS. In the disease condition, exercise has been activated to pro-inflammatory cascades which are able to trigger the leukocytes (Cooper et al., 2007).

Exercise leads to neuroendocrine changes, like increases release of growth hormone may also play a major role in the trigger to the neutrophils (Smith et al., 1996). Neutrophil penetrates into inflammatory sites and then release superoxide anions generated by myeloperoxidase and NADPH oxidase activities. By the help of superoxide dismutase activity and highly reactive hydroxyl radical catalyzed by oxido-reductive active metal ion converts Superoxide to hydrogen peroxide. In rats experimentally feeding of Lipid peroxides lead to change the oxido-reductive mechanism status in gastric mucosal cells and can suppress apoptosis and turnover of epithelial cells (Tsunada et al., 2003). Lipid peroxidation mediated by reactive oxygen species (ROS) is considered as an important cause of oxidative damage and destruction to the cell membrane, changing the structural integrity and biochemical functions of the lipid membrane (Fridovich et al., 1978; Niki et al., 1987). Plasma MDA concentration denotes tissue lipid peroxidation marker (Galunska et al., 2002). Gastrointestinal mucosa detoxifies to the dietary lipid peroxides (Miyamoto et al., 2003) and antioxidant systems may be relatively exhausted by the peroxide intake, consequently changing the cellular redox mechanism. In peripheral tissue, glutathione 
peroxidize (GSH) acts as an electron donor in the glutathione peroxidase-catalyzed reduction of organic and hydrogen peroxides. Therefore, the oxidized glutathione formed through this reaction removed from the cell using NADPH-dependent reduction mechanism by glutathione reductase (Meister et al., 1983; Ehrhart et al., 2003).

\section{Diagnosis}

\section{History and clinical signs}

Gastritis and Peptic Ulcer disease are not depending on breed, age or sex. The disease depends upon history of non-steroidal antiinflammatory drug (NSAIDs) administration, ingestion of foreign materials, chemicals, poisons, coarse food materials and any other systemic disease like hepatic disease, renal disease, tumour, pregnancy gastric or secondary metastases vomiting frequency and contents of vomitus like bile, food, froth, blood (frank or digested) or evidence of an ingested substance (e.g. grass, bones, foreign material, etc).The most common clinical sign of gastric ulcer is acute or chronic vomiting with or without hematemesis. All animals have gastric ulcer should be vomit, but all animals those are vomit blood should not have gastric ulcers (Otto et al., 1991). The most common clinical sign in gastric disease of animals are underweight, pale mucous membrane, tachycardia from severe anaemia or shock, pain on palpation may be observed if there is widespread of perforated ulcer and spread of contamination into the peritoneum, vomiting, haemoptysis, melena, weight loss, anaemia, abdominal pain, inappetence or anorexia, oedema, septicaemia, liver disease, renal diseases, neurologic diseases. Gastric and duodenal perforated ulcers show sign of extensive pain of abdomen, abdominal distension, high fever, shock and death caused by peritonitis. Only mild signs of abdominal disease with perforated ulcers have presented by the animals is rarely reported (Cortese et al., 2010). Gastrointestinal lymphosarcoma induced gastric ulceration produces anorexia, vomiting, diarrhoea, progressive loss of body weight, dullness and depression. In NSAIDs induced ulceration has these similar signs with melena and paleness of the tongue has been observed (Shaw et al., 1997).

\section{Laboratory findings}

In gastric ulcer disease laboratory findings indicated that clinical abnormalities are how much severe (anemia or septic abdominal fluid sample) and prediction of stimulating cause e.g. (renal failure). The main findings of piroxicam induced gastric ulceration are neutrophilic leucocytosis while the. Phenol poisoning induced gastric ulceration has abnormal hematological changes like neutropenia with toxic neutrophils, thrombocytopenia and increased muscular enzymes (Talbert et al., 2012). The important hormone for the maintenance of normal gastric homeostasis is Gastrin-17 (Fourmy et al., 2011) secreted by $\mathrm{G}$ cells of gastric antrum which acts with acetylcholine into receptors of enterochromaffin cells, results in releases of histamine. The secreted histamine binds to receptors on the surface of the parietal cell produces c-AMP whereas Gastrin-17 and acetylcholine open calcium channel leads to stimulating effects on gastric acid secretion from the apical $\mathrm{H}+-\mathrm{K}+$ ATPase (Guarsio et al., 2009). Serum gastrin-17 has become an important biomarker for gastric antrum inflammation (Fourmy et al., 2011). The PGI and PGII are secreted into the gastric lumen and out of the $1 \%$ leaked into circulations (Griti et al., 2000). The Pepsinogen I (PGI) value proportionally decreases with the development of fundic atrophy while Pepsinogen II (PGII) has not shown any pattern with fundic or antral atrophy (Griti et al., 2000). However, the decline in value of PGI to PGII ratio 
(PGI/PGII) has been revealed for detection of fundic atrophy and diagnostic biomarkers for atrophic gastritis and patients with high risk of gastric cancer (Vaanenen et al., 2003; Graham et al., 2006). The gastric diseases, second-degree dehydration, and the sign of shock have been detected by skin fold test and relative polycythemia. It must be required emergency treatment with different haematological test e.g. complete blood count (Total erythrocyte Count, Total leucocyte Count, Total platelet count, Haemoglobin concentration, Packed cell volume), Blood urea nitrogen [BUN], Serum creatinine level, Blood glucose level, AST (aspartate aminotransferase), Alanine aminotransferase (ALT), Alkaline phosphatase (ALP) level and, if available, lactate, $\mathrm{pH}$, and electrolytes levels also measured. ALT, AST, ALP and BUN, Serum creatinine level are the biochemical marker of hepatic disease and renal diseases which also leads to GI ulceration.

Serum Gastrin-17 is the most important biomarker for gastric antrum inflammation (Fourmy et al., 2011). The reference range of serum Gastrin-17 concentration is $10-40 \mathrm{ng} / \mathrm{L}$ (Garcia et al., 2005; Parente et al., 2014). The serum gastrin concentration has been markedly increased in severe gastric disorders (Garcia et al., 2005). Serological biopsy has been reported that serum PG level shows to the morphologic and functional alteration to the gastric environment (Taggart and Samloff, 1987). Serum pepsinogen A level (18 to 129 $\mu \mathrm{g} / \mathrm{L})$ can be used as a diagnostic marker for gastric diseases in the dog (Suchodolski et al., 2002; Suchodolski et al., 2003).

Additional clinico pathological tests are required to detect the liver and renal diseases, hypoadrenocorticism, hypothyroidism, pancreatitis which may lead to gastric mucosal lesions.
Helicobacters organisms produce urease enzyme in gastric mucosa which hydrolyzes urea to ammonia, results increase ammonia concentration in the gastric mucosal layer leads to raises gastric $\mathrm{pH}$ in which bacterial populations were survived (Marshall et al., 1990). Rapid urea test (RUT) and modified rapid urease (MRU) test are used for determination of Helicobacter infection of gastric mucosa in gastric biopsy samples (Katelaris et al., 1992). These organisms also confirmed by phase microscopic examination. Oxidative stress measurement is difficult to perform directly because unpaired electron makes free radical very unstable and high reactive (hence, short half-life) thus, their measurement needs specific tools like, electron spin resonance that can identify compounds with unpaired electrons. In biological samples products of ROS, reactions are easier to measurable through biological assays e.g. measure the DNA adduct 8hydroxy-2'- deoxyguanosine, protein carbonylation, and many lipid breakdown products. Sthiobarbituric acid reactive substances (TBARS), Malondialdehyde, 4hydroxy-2-nonenal, Isoprostane, Ethane, Pentane, and Lipid hydroperoxides are the most Common measurable lipid products. Antioxidants enzymes activity Catalase (CAT) activity (Aebi, 1984) has been determined (U/g $\mathrm{Hb})$ after isolation and lysis of RBCs and glutathione peroxidase (GPx) activity were measured (mU/mg $\mathrm{Hb}$ ) on whole blood. Healthy dogs have a good defense system against oxidative stress that compensated by balanced redox mechanism by revert the overproduction of free radicals and come again to homeostasis. However, most sick animals unable to show this mechanism and it will promote the occurrence of an extreme oxidative stress. This mechanism is possible by production of the antioxidant agents, which prevents from oxidative stress and lead to regeneration of cells, taking the reduced glutathione (GSH), 
superoxide dismutase (SOD), catalase (CAT) and glutathione peroxidase (GPx) enzymes in the frontline (Bae et al.,2011; Naito et al., 2010). It increases the production of $\mathrm{H} 2 \mathrm{O} 2$ in response to the activity of antioxidant enzymes CAT and GPx levels are elevated. Catalase enzyme activity present in all tissues but higher in RBCs, hepatic, renal, adipose tissues and lower in nervous tissue converts hydrogen peroxide $\left(\mathrm{H}_{2} \mathrm{O}_{2}\right)$ to oxygen and water (Pacheco et al., 2009; Zamocky et al., 2008,). GPX enzyme has been used glutathione as a substrate along with other organic hydroperoxides and catalyzes the $\mathrm{H}_{2} \mathrm{O}_{2}$ reduction mechanism (Bae et al., 2011). The acute stage of GI haemorrhage leads to normocytic normochromic anaemia while chronic stage of GI haemorrhage leads to microcytic hypochromic anaemia in iron deficiency anaemia (Waldrop et al., 2003). The acute haemorrhagic diarrhoea with increased haematocrit count and plasma protein concentration indicates haemorrhagic gastroenteritis. The faecal occult blood test should be done in the unclear cases of GI haemorrhage but it gives false positive results due to dietary causes (e.g. vegetables, fruits, red meat, fish meat) or some bacterial population in the alimentary tract so that it suggests that 72 hour before performing of this test meat-free diet fed to the patients. It is generally used for coagulation defects that are not the primary cause of GI haemorrhage but noticeable intensifying blood loss e.g. rodenticide toxicity or clotting factor deficiencies. The Total Platelet count is a very useful measure of coagulation defects. In dogs, immune-mediated thrombocytopenia (ITP) is the common factor of GI haemorrhage. If no any cause of ulceration has been found then electrolyte level can be estimated and ACTH stimulation test should be done because it has been reported that hypo adrenocorticism coupled with GI haemorrhage in dogs (Medinger et al., 1993). The dogs have gastric ulceration and perforation given with IM injection of Pentagastrin, @6 micrograms/Kg body weight leads to elevation of the secretion of gastric juice (hyperacidity).The extent of endoscopically detected damage shows a relationship with sucrose permeability. The decrease in the permeability of sucrose is more quickly than gastric ulcer disappearance. Sucrose permeability test is more responsive for widespread mucosal damage than to distinct common ulceration (Meddings et al., 1995).

\section{Diagnostic imaging}

The plain and contrast radiographs are useful for determining possible origin of abdominal disturbances (gastric foreign bodies) but may be unsatisfactory in smart verification of gastric ulceration (Guarino et al., 2008). The ultrasonography used for recognizing foreign bodies and masses, identification of GI perforation and used to detect drug-induced gastric mucosal changes and sometimes helpful to suggestion for the need of surgery (Boysen et al., 2003). Ultrasonography of the gastrointestinal tract (GIT) is a valuable diagnostic imaging technique in animals (Penninck et al., 1990). The complete abdominal ultrasonographic evaluation by 5 , 7.5 and/or $10 \mathrm{MHz}$ transducers has been performed in all age dogs, gastric lesions are considered by gastric wall thickening, wall layering and contents of gastric lumen. Poor Gastric motility is also considered if the peristaltic movement of the stomach is one or less contraction per minute. Ultrasonography of gastric ulcer can be suspected by the presence of gastric wall thickening associated with a wall defect (crater), gastric fluid accumulation, reduced motility, and constantly accumulation of microbubbles at the crater site (Tomooka et al., 1989; Smithuis et al., 1989). Ultrasonographic findings of the gastric epithelial tumor are gastric wall thickening, pseudolayering, 
poorly echogenic wall and regional or distant lymphadenopathy (Penninck et al., 1998). Endoscopy is the most sensitive diagnostic and prognosis of a diversity of gastrointestinal diseases. Endoscopic examination is important for the diagnosis and provides the perfect diagnosis by direct gastric mucosal visualization, biopsy collection, decided to prognosis and therapeutic benefits (Shaheen et al., 2010). For the diagnosis of gastric mucosal lesions endoscopic examination can be protected, non-invasive, exact and without risk of dehiscence or peritonitis for evaluation of the color and gastric mucosal integrity of gastric mucosal layer (Happe et al., 1983; Grooters et al., 1994).

\section{Differential diagnosis}

Ingestion of specific foods (mainly protein) induces immune-mediated response leads to the sudden onset of gastrointestinal symptoms due to pruritus of the GIT known as food allergy in dogs (Webb and Twedt, 2003). In the starting phase of the gastric neoplasm no clinical sign appears, thus it can be diagnosed at later stages in most cases, therefore, the higher mortality rate has been reported (Tesensuren et al., 2006). The endoscopic examination of gastric neoplasm reveals cauliflower shape cell mass in the gastric wall and therapy based on clinical signs has not been responded. The biochemical examinations reveal elevation of serum creatinine level, the activity of gastric enzymes and serum arginase activity while the level of the total protein concentration especially albumin level reduces (Meram and Tarakçıoğlu, 2000). The male dogs mostly suspected for gastric carcinoma generally originated from pylorus and microscopic examination showed diffused penetration of inadequate differentiated neoplastic cells coupled with scirrhous reaction and gives appearance of typical "signet ring" cells (Brown et al., 2007). Due to obstruction of the lumen or inflammatory pain in the esophagus reveals star grazing behavior and clinical signs that are the regurgitation of food, excessive salivation, dysphagia, frequent tries to swallow, anorexia, and progressive weight loss (Frank et al., 2012). The anesthesia-induced gastro-esophageal reflex leads to esophagitis which is the most common cause of esophageal pain (Poier et $a l$. , 2014). Omeprazole is used for the treatment of the stargazing behavior of dogs due to esophagitis because it enhances gastric $\mathrm{pH}$ (Tolbert et al., 2011). The Bravo pH monitoring system calculates GastroEsophageal reflux, Nuclear scintigraphy, positive contrast esophagogram and fluoroscopy method (GER) in canines (Tolbert et al., 2011). If the dog is suffering from obsessive-compulsive disorder, reveals signs of excessive licking to foreign objects continuously like floor, wall, furnitures, lead to nauseous sensation and discomforts without GIT disorders (Overall et al., 2002; Bonnet et al., 2012) should be treated with combination of serotonergic drug with behavioral therapy (Overall and Dunham, 2002).If the lipolysis mechanism has been disturbed lead to the generation of an excessive amount of ketone bodies which hampers the blood buffer system and development of acidemia with diabetic ketoacidosis (Kerl, 2001). The disturbed lipolysis mechanism will also lead to GI disturbances and produce polyurea, polydipsia, anorexia, vomiting, progressive weight loss, haematuria, pollakiuria, shock and death of the dogs is generally due to a severe metabolic acidosis or complications to the vital and visceral organs (Hume et al., 2006). If the $\mathrm{pH}$ is less than 7.10, bicarbonate and insulin therapy for the treatment of DKA is recommended (Causmaecker et al., 2009). The most important clinical sign of the haemorrhagic gastroenteritis is acute onset of vomiting, profuse bloody diarrhoea, dehydration, and depression. The puppies 
having age between six weeks to six months are more susceptible, but more severe in an age of less than six-month young dogs or old dogs (Sutton et al., 2013). In young one GI system and Cardiac system are mostly affected but only GI system is maximally affected in adult dogs. The parvovirus has been identified with the help of ELISA and PCR. In the condition of shock, rapid infusion (over 10-20 minutes) of a bolus of 10$20 \mathrm{ml} / \mathrm{kg}$ BW of lactated Ringers solution should be administered because lactate has been further converted into bicarbonate in the liver.

\section{Therapy}

\section{Principles of therapy}

The Principles of therapy of gastritis and peptic ulcer diseases are following (a) Withdrawal of food for prevents stimulation of gastric glands. (b) Removal of the etiological factor that is the hepatic failure, hepatic bacterial infection, NSAIDs or corticosteroid therapy.(c) Ulcer healing supported by- i) stabilization of the cardiovascular system and preserve mucosal perfusion by appropriate fluid therapy ii) diminishing gastric acidity iii) shielding from ulcer by cytoprotective agents (iv) correcting secondary circumstances (dehydration, anemia, weight loss).(d) After the stabilized, the perfusion in the patient than broadspectrum antibiotics or combination of antibiotic therapy has been started.

\section{Fluid therapy with gastric mucosal therapy}

Dehydration, relative polycythemia, Hypokalemia, and hyponatremia are commonly found in dogs after vomiting and diarrhoea. Immediate correction of hypokalemia with antispasmodics is required because hypokalemia leads to hindrance in gastric emptying (Rebar et al., 2001; Bichard and Sherding, 2005). Reflux of duodenal contents (bile, pancreatic juice etc) into the stomach can damage the gastric mucosal barrier (Rodriguez et al., 1997). In the druginduced ulcerations, NSAIDs and other steroidal drugs should be stopped; if medication is necessary for therapy of specific disease then it will be considered. GI protectants in combination used for therapy containing $\mathrm{H}-2$ receptor antagonists (cimetidine, ranitidine, famotidine), proton pump inhibitors (omeprazole, pantoprazole), cytoprotectants (sucralfate) and synthetic prostaglandins (misoprostol). Cimetidine is the first $\mathrm{H} 2$ receptor antagonist used in dogs and it is administered 3-4 times daily dose of @ 2.5-5 mg/lb body weight for suppressing gastric acid secretion (Ephgrave et al., 1987). Even so, there is only mild to moderate inhibition of acid secretion over a 24 hours period. The fact that it works clinically for ulcer therapy suggests that even partial suppuration of gastric acid secretion is beneficial for the healing of most gastroduodenal ulcers. In the GI haemorrhage and vomiting in significantly ill dogs, it must be considered dose and route of drug administration because oral route can the drug absorption. Ranitidine @2mg/kg IV q 12 hr has not been shown a major effect on gastric acid suppression (Bersenas et al., 2005). Proton pump inhibitors are the most potent agents for suppression of gastric acid secretion by the inhibition of the gastric $\mathrm{H}+/ \mathrm{K}+-$ ATPase enzyme (the proton pump), which leads to failing the gastric secretion and rising the intragastric mucosal $\mathrm{pH}$ (Miner et al., 2003; Scott et al., 2002). Mainly clinically available proton pump inhibitors (PPI) are omeprazole, esomeprazole, lansoprazole, rabeprazole, and pantoprazole (Miner et al., 2003). Omeprazole is the first PPI that used clinically in 1988 at Losec in Europe, and in 1990 at Prilosec in the United States. Esomeprazole commonly used with omeprazole that is very much effective for 
inhibition of gastric acid secretion (Andersson et al., 2000). The esomeprazole (40 mg) is more effective than lansoprazole $(30 \mathrm{mg}$ ) for healing erosive esophagitis and heartburn condition. For intragastric acid control intravenously once-daily dosing with esomeprazole provides faster and more prominent healing results than intravenously once-daily dosing with pantoprazole (Wilder et al., 2004).In the patients with signs of GERD esomeprazole presents faster and greater acid control results to longer period maintain the intragastric mucosal $\mathrm{pH}$ than lansoprazole, omeprazole, pantoprazole, and rabeprazole (Rohss et al., 2004). Famotidine @ 0.5mg/kg IV q12hr, omeprazole @ $1 \mathrm{mg} / \mathrm{kg}$ orally q24hr) and pantoprazole @ 1mg/kg IV q24hr each have a notable property of the gastric acid secretion in dogs. Omeprazole acts as a Proton pump inhibitor that inhibits the $\mathrm{H}+\mathrm{K}+\mathrm{ATPase}$ pump and the production of hydrochloric acid from gastric parietal cells. Omeprazole enhances regulations of GKNs and produces anti-inflammatory effects, gastric homeostasis and tumor suppression (Kang et al., 2001; Menheniott et al., 2013; Xing et al., 2012). Omeprazole inhibits c-AMP pathway of hydrogen ion generation and leads to prevent ulcer formation and enhance ulcer healing by increasing of gastric mucosal circulation and mucosal epithelial cells migration. The median value of 24-hour intragastric $\mathrm{pH}$ on days 2 and 6 were significantly higher when dogs were given famotidine, pantoprazole, or omeprazole than dogs were given ranitidine (Bersenas et al., 2005). Misoprostol is an analog of PGE2 gives at the doses of 0.5 to $2.3 \mu \mathrm{g} / \mathrm{lb}$ body weight twice in a day. In NSAID induced ulceration, misoprostol may provide additional benefit with sucralfate and $\mathrm{H} 2$ antagonist therapy. Prostaglandin E is contraindicated in hypotensive animals because it may lead to increasing of gastric damage. These drugs shield healthy and uncovered mucosa from more harm and encourage epithelialization of gastric mucosa (Kuwayama et al., 1991). Sucralfate is a nonabsorbable aluminum salt of sucrose octasulfate compound that used as an optional extra to $\mathrm{H}_{2}$ antagonists for treating peptic ulcers, because when ulcerative clinical signs are noticeable It is more effective in NSAIDinduced ulceration than other drugs such as sucralfate and $\mathrm{H}_{2}$ receptor antagonists, so it is choice of drug for NSAIDs producing ulcers (Lanza et al., 2009). Acid-reducing drugs are work on cellular level metabolism to inhibit hydrogen ion secretion (e.g. prostaglandins) (Lanza et al., 2009). Intravenous administration of metoclopramide @1$2 \mathrm{mg} / \mathrm{kg} / 24 \mathrm{hr}$ act as dopamine- antagonists that raise the threshold activity level of chemoreceptor trigger zone in vomiting center and decrease visceral nerve input that prevents vomiting (Sawant et al., 2004). If the GI ulceration is coupled with the acute abdominal pain of unclear etiology, opioid analgesics should be administered for stabilization of GIT motility as well as relieve pain suffering. Antispasmodic drugs (e.g. dicyclomine) can also be administered.

\section{Triple therapy}

In considerable GI haemorrhage, broadspectrum antibiotics should be administered for check the formation of bacterial colonies in the gastric mucosa as well as systemic translocation of the bacterial population. The culture of samples and Antibiotic sensitivity test should be done before started antibiotic therapy. Single Antibiotics does not gives significant effect against Helicobacter spp. Because rapidly development of drug resistance "Triple therapy" is effective against Helicobactor organism; this contains three antibiotic combinations or a combination of two antibiotics and one acid reducing agent like omeprazole or $\mathrm{H}_{2}$ receptor antagonist (Bichard and Shreding, 2005). In H. pylori induced gastric disease, progressive 
diminution of GKNs gene expression is known through disease progression chronic condition to oncogenic transformation (Choi et al., 2013). Removal of $H$. pylori organisms from stomach leads to restoration of normal tissue level for proper expression of GKNs gene (Nardone et al., 2007). Gastric Helicobactor infection treated with "Triple therapy" consisting anioxycillin $20 \mathrm{mg} / \mathrm{kg}$ BID, metronidazole $10 \mathrm{mg} / \mathrm{kg}$ BID and bismuth subcitrate $6 \mathrm{mg} / \mathrm{kg}$ BID orally for two to four weeks. Alternative eradication therapy with tetracycline $20 \mathrm{mg} / \mathrm{kg}$ BID and omeprazole $0.7 \mathrm{mg} / \mathrm{kg} \quad$ OD administered orally for next 10 and 14 days was given after triple therapy for eradication of subsequently persisting helicobacter organism (Happonen et al., 2000). Triple therapy with amoxycillin, metronidazole and famotidine also successfully eradicate gastric Helicobactor infection in $\operatorname{dog}$ and cat (Simpson et al., 2000).

\section{Antioxidant therapy}

It is difficult to prevent the generation of ROS but the proper strategies prevent the gastric mucosal damage and fastening of recovery from oxidative stress. In the diet of sled dog, ROS scavengers such as vitamin $\mathrm{E}$ have been used to diminish cellular damage due to exercise (Hinchcliff et al., 2000). Some antioxidants are used to protect gastrointestinal mucosa and apical epithelial membrane. In rats, the Cacao Liquor watersoluble crude polyphenols (CWSP) has been shown radical scavenging ability as well as reduce ethanol-induced gastric lesions (Osakabe et al., 1998). The normal blood level of vitamin-C is $3.2-8.9 \mathrm{~m} / \mathrm{L}$ in dogs, (Hishiyama et al., 2006). Vitamin $-\mathrm{C}$ is necessarily required for absorption of antioxidants like $\mathrm{N}$ - acetylcysteine, and alphatocopherol in young dogs while in geriatric patient, the oral dosage of Vitamine $\mathrm{C}$ gives minor antioxidant and immunological effects
(Hall et al., 2006; Ogawa et al., 2008; Hesta et al., 2009). Ascorbic acid reduces oxidative damage to the gastric mucosal layer by scavenging ROS and attenuating the $\mathrm{H}$. pylori-induced inflammatory cascade leads to decreased incidence of gastric carcinoma and bleeding from peptic ulcer disease (Aditi et $a l .$, 2012). During scavenging of free oxygen radicals by ascorbic acid produces 2-fold greater amount of ascorbyl radicals in the $\mathrm{H}$. pylori-infected gastric mucosa (Drake et al., 1998). Vitamin C is also an important dietary antioxidant because it significantly decreases the adverse effect of reactive oxygen species (ROS) that is a source of oxidative damage to the cell components like, lipids membrane, DNA, and proteins (Maestro et al., 1980; Iheanacho et al., 1993). Vitamin C is the only antioxidant required for complete protection of endogenous lipids from noticeable oxidative damage induced by ROS (Polidori et al., 2004). Before the reaction and oxidation of lipoprotein lipids, Ascorbate seizes the activity of ROS. If serum concentration of Vitamin $\mathrm{C}$ has been down, the remaining antioxidants cannot be able to provide complete protection from ROS, leads to oxidative stress and initiate lipid peroxidation (Ulutas et al., 2006).

$\mathrm{N}$ - Acetylcysteine works have mucolytic as well as antioxidant effect and reduce colonization of Helicobacter organism in gastric mucosa (Huynh et al., 2000). Nacetylcysteine increases liver blood flow and improves liver function and renal function, as well as hepatorenal syndrome, lead to reduce severity of systemic induced gastritis (Holt et al., 1999; Rank et al., 2000). Silymarin significantly affects the serum SGPT, SGOT, Alkaline phosphatase activities, serum urea and creatinine levels and maintains malondialdehyde level (MDA) as an antioxidant in liver and kidney (El-Maddawy et al., 2012). 


\section{Others}

New synthetic flavonoid derivatives gastroprotactant drugs are also used for the treatment of gastritis and peptic ulcer disease. It was designed by effervescent floating matrix system (EFMS) that float the tablet in gastric fluids and constant release of drug DA-6034 from tablets in acidic media. It acts as solubilizing and alkalizing agent like as sodium bicarbonate has been used as a gas generating agent. DA-6034 EFMS tablets lead to enhancing the gastroprotective effects of gastric ulcer, gastritis and peptic ulcer (Jang et al., 2008). Electron microscopic examination showed abundant osmophilic phospholipids materials are found as a surfactant within the mucosa of gastric and duodenum and administration of phospholipids exogenously may prevent gastric mucosal ulceration (Ethell et al., 1999). If ulcer patient co-existing with motility disorders of delayed gastric emptying also give Cisapride therapy (Natan et al., 1996). Therapy of severe bleeding in acute GI haemorrhage depends on the degree and length of bleeding time and PCV. Whole blood or oxyglobin transfusion is the first protocol of recovery. Blood transfusion in unclearly observed rate and volume of blood loss in patients who do not show sign of shock causes vascular hemodynamic abnormalities, disturbances in haematological parameters, and parallel illness are noticed (Maltz et al., 2000). It may be required if the patient shows clinical signs of hypoxia (e.g. tachycardia, hyper-lactataemia, tachypnoea), or if series of haematological parameters showed failing haematocrit value after the therapy started (Maltz et al., 2000). If the medical therapy fails to respond, surgery should be indicated for pre-existing surgical disease (e.g. perforated ulcer, foreign body or tumours, septic abdomen), Before therapy of GI haemorrhage, it must be considered in hepatic disease (coagulation abnormalities) and renal diseases (uraemia), otherwise it may lead to intensifying the condition.

\section{References}

Abdel-Salam, O. M., Czimmer, J., Debreceni, A., Szolcsányi, J., and Mózsik, G. 2001. Gastric mucosal integrity: gastric mucosal blood flow and microcirculation. An overview. J. Physiol. Paris. 95(1): 105-127.

Aditi, A., and Graham, D. Y. 2012. Vitamin $\mathrm{C}$, gastritis, and gastric disease: a historical review and update. Dig. Dis. Sci., 57(10): 2504-2515.

Amorim, I., Taulescu, M. A., Day, M. J., Catoi, C., Reis, C. A., Carneiro, F., and Gärtner, F. (2016). Canine gastric pathology: a review. J. Comp. Pathol. 154(1): 9-37.

Anacleto, T. P., Lopes, L. R., Andreollo, N. A., Bernis Filho, W. O., Resck, M. C. C., and Macedo, A. (2011). Studies of distribution and recurrence of Helicobacter spp. gastric mucosa of dogs after triple therapy. Acta. Cir. Bras. 26(2): 82-87.

Andersson, T., Rohss, K., Hassan-Alin, M. and Bredberg, E. 2000. Pharmacokinetics (PK) and doseresponse relationship of esomeprazole (E). Gastroenterology. 118(4): A1210.

Atsbaha, G., Hussien, D. and Cruz, R. C. 2014. Assessment of Major Health Problems of Dogs in Mekelle City, Ethiopia. Glob. Vet. 12(2): 176-180.

Bae, Y. S., Oh, H., Rhee, S. G., and Do Yoo, Y. 2011. Regulation of reactive oxygen species generation in cell signaling. Molecules and cells, 32(6): 491-509.

Bailey, W. S. (1963). Parasites and cancer: sarcoma in dogs associated with Spirocerca lupi. Ann. N. Y. Acad. Sci., 108(1), 890-923.

Bar-Natan, M., Larson, G.M., Stephens, G. and Massey, T. 1996. Delayed gastric 
emptying after gastric surgery. Am. J. Surg. 172(1):24-28.

Bécuwe-Bonnet, V., Bélanger, M. C., Frank, D., Parent, J., and Hélie, P. 2012. Gastrointestinal disorders in dogs with excessive licking of surfaces. J. Vet. Behav. Clinical Applications and Research, 7(4): 194-204.

Bersenas, A. M., Mathews, K. A., Allen, D. G., \& Conlon, P. D. 2005. Effects of ranitidine, famotidine, pantoprazole, and omeprazole on intragastric $\mathrm{pH}$ in dogs. Am. J. Vet. Res. 66(3): 425-431.

Bersenas, A. M., Mathews, K. A., Allen, D. G., and Conlon, P. D. 2005. Effects of ranitidine, famotidine, pantoprazole, and omeprazole on intragastric $\mathrm{pH}$ in dogs. Am. J. Vet. Res. 66(3): 425-431.

Birchard, S. J., and Sherding, R. G. (2005). Saunders Manual of Small Animal Practice-E-Book. Elsevier Health Sciences.

Biswas, K., Bandyopadhyay, U., Chattopadhyay, I., Varadaraj, A., Ali, E., Banerjee, R. K. 2003. A novel antioxidant and antiapoptotic role of omeprazole to block gastric ulcer through scavenging of hydroxyl radical. J. Biol. Chem. 278(13): 10993-11001.

Boston, S. E., Moens, N. M., Kruth, S. A., Southorn, E. P. 2003. Endoscopic evaluation of the gastroduodenal mucosa to determine the safety of shortterm concurrent administration of meloxicam and dexamethasone in healthy dogs. Am. J. Vet. Res. 64(11): 1369-1375.

Boysen, S. R., Tidwell, A. S., Penninck, D. G. 2003. Ultrasonographic findings in dogs and cats with gastrointestinal perforation. Vet. Radiol. Ultrasound. 44(5): 556-564.

Breitschwerdt, $\quad$ E. $\quad$ B. 1992. Immunoproliferative enteropathy of Basenjis. In Semin. Vet. Med. Surg. (Small. Anim.) (USA).
Brown, C. C., Baker, D. C., Barker, I. K 2007. Neoplastic and proliferative lesions of the stomach and intestine. Grant Maxie M (ed.): Jubb, Kennedy \& Palmer's Pathology of Domestic Animals. Saunders Ltd, 116-127.

Burrows, C. F. 1983. Infection with the stomach worm Physaloptera as a cause of chronic vomiting in the dog. J. Am. Anim. Hosp. Assoc. 19(6): 947-950.

Cecchi, R., Wills, S. J., Dean, R., Pearson, G. R. 2006. Demonstration of Ollulanus tricuspis in the stomach of domestic cats by biopsy. J. Comp. Pathol. 134(4): 374-377.

Chatelain, D., Attencourt, C., Flejou, J. F. 2014. Les classifications des gastrites: mise au point. R.F.L. 2014(458): 31-40.

Chira, O., Badea, R., Dumitrascu, D., Serban, A., Branda, H., al Hajjar, N., Cruciat, C. 2005. Eosinophilic Ascites in a Patient with Toxocara Canis Infection. J. Gastrointestin. Liver Dis. 14(4): 397400.

Choi, W. S., Seo, H. S., Song, K. Y., Yoon, J. H., Kim, O., Nam, S. W., and Park, W. S. 2013. Gastrokine 1 expression in the human gastric mucosa is closely associated with the degree of gastritis and DNA methylation. J. Gastric Cancer. 13(4): 232-241.

Chu, S. and Schubert, M. L. 2012. Gastric secretion. Curr. Opin. Gastroenterol. 28(6): 587-593.

Chung, T. H., Kim, H. D., Lee, Y. S., and Hwang, C. Y. 2014. Determination of the prevalence of Helicobacter heilmannii-like organisms type 2 (HHLO-2) infection in humans and dogs using non-invasive genus/speciesspecific PCR in Korea. J. Vet. Med. Sci. 76(1): 73-79.

Clark, J. A. 1990. Physaloptera stomach worms associated with chronic vomition in a dog in Western Canada. Can. Vet. J. 31(12): 840. 
Cooper, D. M., Radom-Aizik, S., Schwindt, C., and Zaldivar, F. 2007. Dangerous exercise: lessons learned from dysregulated inflammatory responses to physical activity. J. Appl. Physiol. 103(2): 700-709.

Cortese, M. M., Tate, J. E., Simonsen, L., Edelman, L., and Parashar, U. D. 2010. Reduction in gastroenteritis in United States children and correlation with early rotavirus vaccine uptake from national medical claims databases. Pediatr. Infect. Dis. J. 29(6): 489-494.

Davies, N. M., Saleh, J. Y., \& Skjodt, N. M. 2000. Detection and prevention of NSAID-induced enteropathy. J. Pharm. Pharm. Sci. 3(1): 137-155.

Davis, M. S., Willard, M. D., Nelson, S. L., Mandsager, R. E., McKiernan, B. S., Mansell, J. K., and Lehenbauer, T. W. 2003. Prevalence of gastric lesions in racing Alaskan sled dogs. J. Vet. Intern. Med. 17(3): 311-314.

Day, M. J., Biltzer, T. and Mansel, J. 2008. World Small Animal Veterinary Association Gastrointestinal Standardization Group. Histopathological standards for the diagnosis of gastrointestinal inflammation in endoscopic biopsy samples from the dog and cat: a report from the World Small Veterinary Association Gastrointestinal Standardization Group. J. Comp. Pathol. 138: S1-S43.

De Causmaecker, V., Daminet, S., and Paepe, D. 2009. Diabetes ketoacidosis and diabetes ketosis in 54 dogs: a retrospective study. Vlaams Diergeneeskd. Tijdschr. 78: 327-337.

Del Maestro, R. F. 1980. An approach to free radicals in medicine and biology. Acta. Physiol. Scand. Suppl. 492: 153-168.

Ditchfield, J., and Phillipson, M. H. 1960. Achlorhydria in dogs, with report of a case complicated by avitaminosis C. Can. Vet. J. 1(9): 396.

Dow, S. W., Rosychuk, R. A., McChesney, A. E., and Curtis, C. R. 1990. Effects of flunixin and flunixin plus prednisone on the gastrointestinal tract of dogs. Am. J. Vet. Res. 51(7): 1131-1138.

Dowdle, S. M., Joubert, K. E., Lambrechts, N. E., Lobetti, R. G., and Pardini, A. D. 2003. The prevalence of subclinical gastroduodenal ulceration in Dachshunds with intervertebral disc prolapse. J. S. Afr. Vet. Assoc. 74(3): 77-81.

Drake, I. M., Mapstone, N. P., Schorah, C. J., White, K. L. M., Chalmers, D. M., Dixon, M. F., and Axon, A. T. R. 1998. Reactive oxygen species activity and lipid peroxidation inHelicobacter pylori associated gastritis: relation to gastric mucosal ascorbic acid concentrations and effect of $\mathrm{H}$ pylori eradication. Gut, 42(6): 768-771.

Ectors, N. L., Dixon, M. F., Geboes, K. J., Rutgeerts, P. J., Desmet, V. J., and Vantrappen, G. R. 1993. Granulomatous gastritis: a morphological and diagnostic approach. Histopathology, 23(1): 55-61.

Ehrhart, J., \& Zeevalk, G. D. 2003. Cooperative interaction between ascorbate and glutathione during mitochondrial impairment in mesencephalic cultures. J. Neurochem. 86(6): 1487-1497.

Ekman, E., Fredriksson, M., and TrowaldWigh, G. 2013. Helicobacter spp. in the saliva, stomach, duodenum and faeces of colony dogs. Vet. J. 195(1): 127-129.

El-Maddawy, Z. K., and Gad, S. B. (2012). Hepato-renal protection of silymarin in comparison with vitamin $\mathrm{E}$ in rats. Glob. J. Pharmacol. 6(3): 236-244.

Elwood, C., Devauchelle, P., Elliott, J., Freiche, V., German, A. J., Gualtieri, M., and Roura, X. 2010. Emesis in 
dogs: a review. J. Small Anim. Pract. 51(1): 4-22.

Enberg, T. B., Braun, L. D., and Kuzma, A. B. 2006. Gastrointestinal perforation in five dogs associated with the administration of meloxicam. J. Vet. Emerg. Crit. Care, 16(1): 34-43.

Ephgrave, K. S., and Horton, J. W. 1987. Comparison of approaches to stress ulcer prophylaxis in hemorrhagic shock. J. Surg. Res. 43(1): 52-61.

Ethell, M. T., Hodgson, D. R., and Hills, B. A. 1999. Ultrastructure of the hydrophobic gastric surfactant barrier in the dog. Aust. Vet. J., 77(4): 240-244.

Ettinger, S. J. and Feldman, E. C. 2005. Textbook of veterinary internal medicine

Fourmy, D., Gigoux, V., and Reubi, J. C. 2011. Gastrin in gastrointestinal diseases. Gastroenterol. 141(3): 814818.

Frank, D., Bélanger, M. C., Bécuwe-Bonnet, V., and Parent, J. 2012. Prospective medical evaluation of $7 \mathrm{dogs}$ presented with fly biting. Can. Vet. J. 53(12): 1279.

Fridovich, I. 1978. The biology of oxygen radicals. Sci. 201(4359): 875-880.

Gal, A., Ridgway, M. D., and Fredrickson, R. L. 2011. An unusual clinical presentation of a dog with gastrinoma. Can. Vet. J. 52(6): 641.

Galunska, B., Marazova, K., Yankova, T., Popov, A., Frangov, P., Krushkov, I., \& Di Massa, A. 2002. Effects of paracetamol and propacetamol on gastric mucosal damage and gastric lipid peroxidation caused by acetylsalicylic acid (ASA) in rats. Pharmacol. Res. 46(2): 141-148.

García-Sancho, M., Rodríguez-Franco, F., Sainz, Á., Rodríguez, A., Silván, G., and Illera, J. C. 2005. Serum gastrin in canine chronic lymphocytic-plasmacytic enteritis. Can. Vet. J. 46(7): 630.
Gencosmanoglu, R., Sen-Oran, E., KurtkayaYapicier, O., and Tozun, N. 2003. Antral hyperplastic polyp causing intermittent gastric outlet obstruction: case report. BMC Gastroenterol. 3(1): 16.

Gieger, T.L., Correa, S.S., Taboada, J., Grooters, A.M. and Johnson, A.J. 2000. Phenol poisoning in three dogs. J. Am. Anim. Hosp. Assoc. 36(4): 317-321.

Godshalk, C. P., Roush, J. K., Fingland, R. B., Sikkema, D., and Vorhies, M. W. 1992. Gastric perforation associated with administration of ibuprofen in a dog. J. Am. Vet. Med. Assoc. 201(11): 1734-1736.

Graham, D. Y., Nurgalieva, Z. Z., El-Zimaity, H. M., Opekun, A. R., Campos, A., Guerrero, L. and Cardenas, V. 2006. Noninvasive versus histologic detection of gastric atrophy in a Hispanic population in North America. Clin. Gastroenterol. and Hepatol. 4(3): 306314.

Gralnek, I. M., Barkun, A. N., and Bardou, M. 2008. Management of acute bleeding from a peptic ulcer. N. Engl. J. Med. 359(9): 928-937.

Gritti, I., Banfi, G. and Roi, G. S. 2000. Pepsinogens: physiology, pharmacology pathophysiology and exercise. Pharmacol. Res. 41(3): 265-281.

Grooters, A. M., and Gee, M. K. 2002. Development of a nested polymerase chain reaction assay for the detection and identification of Pythium insidiosum. J. Vet. Intern. Med. 16(2): 147-152.

Grooters, A. M., Johnson, S. E. and Sherding, R. G. 1994. Endoscopy case of the month: Chronic vomiting and weight loss in a dog. Vet. Med. 89(3): 196-199.

Grooters, A. M., Sherding, R. G., Biller, D. S., and Johnson, S. E. 1994. Hepatic abscesses associated with diabetes 
mellitus in two dogs. J. Vet. Intern. Med. 8(3): 203-206.

Guarino, A. 2008. Foreword: ESPGHAN/ESPID evidence-based guidelines for the management of acute gastroenteritis in children in Europe. J. Pediatr. Gastroenterol. Nutr. 46: vii-viii.

Guariso, G., Basso, D., Bortoluzzi, C. F., Meneghel, A., Schiavon, S., Fogar, P. and Zambon, C. F. 2009. GastroPanel: evaluation of the usefulness in the diagnosis of gastroduodenal mucosal alterations in children. Clinica Chimica Acta. 402(1): 54-60.

Guilford, W. G., Center, S. A., Strombeck, D. R., Williams, D. A., and Meyer, D. J. 1996. Strombeck's small animal gastroenterology (No. Ed. 3,). WB Saunders Co..

Hall, E. V., and Simpson, K. W. 2000. Diseases of the small intestine. Textbook of veterinary internal medicine: diseases of the dog and cat, Volumes 1 and 2., (Ed. 5): 1182-1238.

Hall, J. A., Picton, R. A., Finneran, P. S., Bird, K. E., Skinner, M. M., Jewell, D. E., \& Zicker, S. 2006. Dietary antioxidants and behavioral enrichment enhance neutrophil phagocytosis in geriatric Beagles. Vet. Immunol. Immunopathol. 113(1): 224-233.

Halliwell, B. 1990. Free radicals and catalytic metal ions in human disease: an over view. Methods Enzymol. 186: 1-85.

Halliwell, B. 1994. Free radicals, antioxidants, and human disease: curiosity, cause, or consequence?. The lancet, 344(8924): 721-724.

Hamir, A. N., and Sullivan, N. D. 1983. Extra- neural lesions in experimental lead toxicosis of dogs. J. Small. Anim. Pract. 24(7): 437-444.

Happe, R. P. and Gaag, I. V. D. 1983. Endoscopic examination of esophagus, stomach, and duodenum in the dog. J. Am. Anim. Hospital Assoc. (USA).
Happonen, I., Linden, J., and Westermarck, E. 2000. Effect of triple therapy on eradication of canine gastric helicobacters and gastric disease. J. Small Anim. Pract. 41(1): 1-6.

Hayden, D. W., and Fleischman, R. W. 1977. Scirrhous eosinophilic gastritis in dogs with gastric arteritis. Vet. Pathol. 14(5): 441-448.

Helman, R. G., and Oliver 3rd, J. 1999. Pythiosis of the digestive tract in dogs from Oklahoma. J. Am. Anim. Hosp. Assoc. 35(2): 111-114.

Henderson, A. K. and Websterm, C. R. 2006. Disruption of the gastric mucosal barrier in dogs. Comp on continuing education for the practising Vetaerinarian- North American Ed. 28(5): 340.

Henderson, A. K., and Webster, C. R. 2006. An In-- Depth Look: Disruption of the Gastric Mucosal Barrier in Dogs. Compendium.

Hesta, M., Ottermans, C., Krammer- Lukas, S., Zentek, J., Hellweg, P., Buyse, J., \& Janssens, G. P. J. 2009. The effect of vitamin $\mathrm{C}$ supplementation in healthy dogs on antioxidative capacity and immune parameters. J. Anim. Physiol. Anim. Nutr. 93(1): 26-34.

Hinchcliff, K. W., Reinhart, G. A., DiSilvestro, R., Reynolds, A., BlosteinFujii, A., and Swenson, R. A. 2000. Oxidant stress in sled dogs subjected to repetitive endurance exercise. Am. J. Vet. Res. 61(5): 512-517.

Hishiyama, N., Kayanuma, H., Matsui, T., Yano, H., Suganuma, T., Funaba, M., \& Fujise, H. 2006. Plasma concentration of vitamin $\mathrm{C}$ in dogs with a portosystemic shunt. Can. J. Vet. Res., 70(4): 305.

Hughes, S. M. 2006. Canine gastrinoma: a case study and literature review of therapeutic options. N. Z. Vet. J. 54(5): 242-247. 
Hume, D. Z., Drobatz, K. J., and Hess, R. S. 2006. Outcome of dogs with diabetic ketoacidosis: 127 dogs (1993-2003). J. Vet. Intern. Med. 20(3): 547-555.

Huynh, H., Couper, R. L., Tran, C. D., Lim, M., Lawrence, A., and Butler, R. N. 2000. N-acetyl-cysteine-A Novel Treatment For Helicobacter pylori Infection. Journal of Gastroenterology and Hepatology, 15: 66.

Iheanacho, E. N., Stocker, R., \& Hunt, N. H. 1993. Redox metabolism of vitamin $\mathrm{C}$ in blood of normal and malaria-infected mice. Biochim. Biophys. Acta. Mol. Basis Dis. 1182(1): 15-21.

Jacobson, E. D. 1992. Circulatory mechanisms of gastric mucosal damage and protection. Gastroenterol. 102(5): 1788-1800.

Jang, S. W., Lee, J. W., Park, S. H., Kim, J. H., Yoo, M., Na, D. H., and Lee, K. C. 2008. Gastroretentive drug delivery system of DA-6034, a new flavonoid derivative, for the treatment of gastritis. Int. J. Pharm. 356(1): 88-94.

Jergens AE. Diseases of the esophagus. In: Ettinger SJ, Feldman EC, eds. Textbook of Veterinary Internal Medicine. 7th ed. St. Louis, Missouri: Saunders, 2010:1487-1499.

Kang, B., Alderman, B. M., Nicoll, A. J., Cook, G. A., and Giraud, A. S. 2001. Effect of omeprazole- induced achlorhydria on trefoil peptide expression in the rat stomach. J. Gastroenterol. Hepatol. 16(11): 12221227.

Katelaris, P. H., Lowe, D. G., Norbu, P., and Farthing, M. J. G. 1992. Field evaluation of a rapid, simple and inexpensive urease test for the detection of Helicobacter pylori. J. Gastroenterol. Hepatol. 7(6): 569-571.

Kato, D., Oishi, M., Ohno, K., Nakashima, K., Wada, A., Morita, T., and Tsujimoto, H. 2015. The first report of the ante-mortem diagnosis of Ollulanus tricuspis infection in two dogs. J. Vet. Med. Sci. 77(11): 1499-1502.

Kawano, S., and Tsuji, S. 2000. Role of mucosal blood flow: a conceptional review in gastric mucosal injury and protection. J. Gastroenterol. Hepatol. 15(s1): 1-6.

Kerl, M. E. 2001. Diabetic ketoacidosis: pathophysiology and clinical and laboratory presentation. Compendium, 23(3): 220-228.

Kuwayama, H., Matsuo, Y., and Eastwood, G. L. 1991. Effects of sucralfate, lansoprazole, and cimetidine on the delayed healing by hydrocortisone sodium phosphate of chronic gastric ulcers in the rat. Am. J. Med. 91(2): S15-S19.

Lanza, F. L., Chan, F. K., and Quigley, E. M. 2009. Guidelines for prevention of NSAID-related ulcer complications. Am. J. Gastroenterol. 104(3): 728.

Lee, A., Krakowka, S., Fox, J. G., Otto, G., Eaton, K. A., and Murphy, J. C. 1992. Role of Helicobacter felis in chronic canine gastritis. Vet. Pathol. 29(6): 487494.

Lewin, A., and Lavon, H. 1997. The effect of coenzyme Q 10 on sperm motility and function. Mol. Aspects Med. 18: 213219.

Lidbury, J. A., Suchodolski, J. S., and Steiner, J. M. 2009. Gastric histopathologic abnormalities in dogs: 67 cases (20022007). J. Am. Vet. Med. Assoc. 234(9): 1147-1153.

Limón-Pacheco J. and Gonsebatt M.E. 2009. The role of antioxidants and antioxidant-related enzymes in protective responses to environmentally induced oxidative stress. Mutation Research. 674(1): 137-147.

Lin Blache J, Ryan K, ArceneauxK. 2011. Histoplasmosis. Compendium on 
Continuing Education for the Practicing Veterinarian, 33: E1eE10.

Luo, J. C., Shin, V. Y., Liu, E. S., Yi, N. Y., $\mathrm{Wu}, \mathrm{W}$. K., So, W. H., and Cho, C. H. 2004. Dexamethasone delays ulcer healing by inhibition of angiogenesis in rat stomachs. Eur. J. Pharmacol. 485(1): 275-281.

Mahmud, T., Rafi, S. S., Scott, D. L., Wrigglesworth, J. M., \& Bjarnason, I. 1996. Nonsteroidal antiinflammatory drugs and uncoupling of mitochondrial oxidative phosphorylation. Arthritis Rheum. 39(12): 1998-2003.

Maleewong, W., Pariyanonda, S., Sitthithaworn, P., Daenseegaew, W., Pipitgool, V., Tesana, S., and Morakote, N. 1992. Seasonal variation in the prevalence and intensity of canine Gnathostoma spinigerum infection in northeastern Thailand. J. Helminthol. 66(1): 72-74.

Maltz, G. S., Siegel, J. E., and Carson, J. L. 2000. Hematologic management of gastrointestinal bleeding. Gastroenterol. Clin. North Am. 29(1): 169-187.

Marshall, B. J., Barrett, L. J., Prakash, C., McCallum, R. W., and Guerrant, R. L. 1990. Urea protects Helicobacter (Campylobacter) pylori from the bactericidal effect of acid. Gastroenterol. 99(3): 697-702.

Martin, G., Wex, T., Treiber, G., Malfertheiner, P., and Nardone, G. 2008. Low- dose aspirin reduces the gene expression of gastrokine- 1 in the antral mucosa of healthy subjects. Aliment. Pharmacol. Ther. 28(6): 782788.

Mastaloudis, A., Leonard, S. W., and Traber, M. G. 2001. Oxidative stress in athletes during extreme endurance exercise. Free Radic. Biol. Med. 31(7): 911-922.

Mathews, K. A., Paley, D. M., Foster, R. A., Valliant, A. E., and Young, S. S. 1996. A comparison of ketorolac with flunixin, butorphanol, and oxymorphone in controlling postoperative pain in dogs. Can. Vet. J. 37(9): 557.

Maxie, M. G. 2007. Jubb, Kennedy, and Palmer's pathology of domestic animals.

McCarthy, J., and Moore, T. A. 2000. Emerging helminth zoonoses. Int. J. Parasitol. 30(12): 1351-1359.

Meddings, J. B., Kirk, D., and Olson, M. E. 1995. Noninvasive detection of nonsteroidal anti-inflammatory druginduced gastropathy in dogs. 56(8): 977-981.

Medinger, T. L., Williams, D. A., and Bruyette, D. S. 1993. Severe gastrointestinal tract hemorrhage in three dogs with hypoadrenocorticism. J. Am. Vet. Med. Assoc. 202(11): 18691872.

Meister, A., \& Anderson, M. E. 1983. Glutathione. Annu. Rev. Biochem., 52(1): 711-760.

Menheniott, T. R., Kurklu, B., and Giraud, A. S. 2013. Gastrokines: stomach-specific proteins with putative homeostatic and tumor suppressor roles. Am. J. Physiol. Gastrointest. Liver Physiol. 304(2): G109-G121.

Meram, İ., Ahi, S., and Tarakçıoğlu, M. 2000. Kanserde serum arginaz aktivitesi. Van. Tip. Dergisi. 7(1): 20-23.

Miner, P., Katz, P. O., Chen, Y. and Sostek, M. 2003. Gastric acid control with esomeprazole, lansoprazole, omeprazole, pantoprazole, and rabeprazole: a five-way crossover study. Am. J. Gastroenterol. 98(12): 26162620.

Mingatto, F. E., Dos Santos, A. C., Rodrigues, T., Pigoso, A. A., Uyemura, S. A., \& Curti, C. (2000). Effects of nimesulide and its reduced metabolite on mitochondria. Br. J. Pharmacol. 131(6): 1154-1160. 
Miyamoto, S., Dupas, C., Murota, K., and Terao, J. 2003. Phospholipid hydroperoxides are detoxified by phospholipase A 2 and GSH peroxidase in rat gastric mucosa. Lipids, 38(6): 641-649.

Mulyangote, L. T. 2016. Ethnobotany and bioactivity of medicinal plants used to treat symptoms associated with gastrointestinal infections in Namibia (Doctoral dissertation, University of Namibia).

Murphy, M. P., \& Smith, R. A. 2000. Drug delivery to mitochondria: the key to mitochondrial medicine. Adv. Drug Deliv. Rev. 41(2): 235-250.

Naito, Y., Masaichi, C. I. L., Kato, Y., Nagai, R., and Yonei, Y. 2010. Oxidative stress markers. J. Anti. Aging Med. 7(5): 3644.

Nardone, G., Martin, G., Rocco, A., La Monica, G., Rippa, E., Caruso, F., and Arcari, P. 2008. Molecular expression of Gastrokine 1 in normal mucosa and in Helicobacter pylori-related preneoplastic and neoplastic gastric lesions. Cancer Biol. Ther. 7(12), 18901895.

Neiger R. 2008. Disease of the stomach. In: Small Animal Gastroenterology, JM Steiner, Ed., Schluetersche, Hannover, 158-175.

Neiger, R., and Simpson, K. W. 2000. Helicobacter infection in dogs and cats: facts and fiction. J. Vet. Intern. Med. 14(2): 125-133.

Neiger, R., Gaschen, F., and Jaggy, A. 2000. Gastric mucosal lesions in dogs with acute intervertebral disc disease: characterization and effects of omeprazole or misoprostol. J. Vet. Intern. Med. 14(1): 33-36.

Niki, E. 1987. Antioxidants in relation to lipid peroxidation. Chem. Phys. Lipids. 44(24): 227-253.
Ogawa, E. 2008. Age-dependent changes in uptake and recycling of ascorbic acid in erythrocytes of Beagle dogs. J. Comp. Physiol. B. 178(6): 699-704.

Osakabe, N., Sanbongi, C., Yamagishi, M., Takizawa, T., and Osawa, T. 1998. Effects of polyphenol substances derived from Theobroma cacao on gastric mucosal lesion induced by ethanol. Biosci. Biotechnol. Biochem. 62(8): 1535-1538.

Otte, J. A., Oostveen, E., Geelkerken, R. H., Groeneveld, A. J., and Kolkman, J. J. 2001. Exercise induces gastric ischemia in healthy volunteers: a tonometry study. J. Appl. Physiol. 91(2): 866-871.

Otto, C. M., Dodds, W. J., and Greene, C. E. 1991. Factor XII and partial prekallikrein deficiencies in a dog with recurrent gastrointestinal hemorrhage. J. Am. Vet. Med. Assoc. 198(1): 129-131.

Overall, K. L., \& Dunham, A. E. 2002. Clinical features and outcome in dogs and cats with obsessive-compulsive disorder: 126 cases (1989-2000). J. Am. Vet. Med. Assoc. 221(10): 1445-1452.

Ozaki K., Yamagami T., Nomura K., Narama I. 2002. Mast cell tumors of the gastrointestinal tract in 39 dogs. Vet. Pathol. 39: 557-564.

Papazoglou, L. G., Patsikas M. N. and Rallis T. 2003. Intestinal Foreign Bodies In Dogs And Cats. Compendium on Continuing Education For The Practising Veterinarian-North American Edition-, 25(11): 830-845.

Parente, N. L., Bari Olivier, N., Refsal, K. R., and Johnson, C. A. 2014. Serum concentrations of gastrin after famotidine and omeprazole administration to dogs. J. Vet. Intern. Med. 28(5): 1465-1470.

Parrah, J. D., Moulvi, B. A., Gazi, M. A., Makhdoomi, D. M., Athar, H., Dar, S., and Mir, A. Q. 2013. Gastric ulceration in dog: A review. World, 6(7): 449-454. 
Penninck, D. G., Moore, A. S., and Gliatto, J. 1998. Ultrasonography of canine gastric epithelial neoplasia. Vet. Radiol. Ultrasound, 39(4): 342-348.

Penninck, D. G., Nyland, T. G., Kerr, L. Y., and Fisher, P. E. 1990. Ultrasonographic evaluation of gastrointestinal diseases in small animals. Vet. Radiol. Ultrasound, 31(3): 134-141.

Perry, H., and Shannon, M. W. 1998. Acetaminophen. Clinical Management of Poisoning and Drug Overdose. Philadelphia, PA: WB Saunders, 664674.

Peters, R. M., Goldstein, R. E., Erb, H. N., and Njaa, B. L. 2005. Histopathologic features of canine uremic gastropathy: a retrospective study. J. Vet. Intern. Med. 19(3): 315-320.

Peterson, A. J., Menheniott, T. R., O'Connor, L., Walduck, A. K., Fox, J. G., Kawakami, K., and Giraud, A. S. (2010). Helicobacter pylori infection promotes methylation and silencing of trefoil factor 2, leading to gastric tumor development in mice and humans. Gastroenterol. 139(6): 2005-2017.

Poirier-Guay, M. P., Bélanger, M. C., and Frank, D. 2014. Star gazing in a dog: Atypical manifestation of upper gastrointestinal disease. Can. Vet. J. 55(11): 1079.

Polidori, M. C., Mecocci, P., Levine, M., \& Frei, B. 2004. Short-term and long-term vitamin $\mathrm{C}$ supplementation in humans dose-dependently increases the resistance of plasma to ex vivo lipid peroxidation. Arch. Biochem. Biophys. 423(1): 109-115.

Polzin, D. J., and Osborne, C. A. 1995. Pathophysiology of renal failure and uremia. Canine and feline nephrology and urology. Philadelphia: Williams \& Wilkins, 335-367.
Pratt, C. L., Reineke, E. L., and Drobatz, K. J. 2014. Sewing needle foreign body ingestion in dogs and cats: 65 cases (2000-2012). J. Am. Vet. Med. Assoc. 245(3): 302-308.

Qamar, M. I., and Read, A. E. 1987. Effects of exercise on mesenteric blood flow in man. Gut, 28(5): 583-587.

Radak, Z., Ogonovszky, H., Dubecz, J., Pavlik, G., Sasvari, M., Pucsok, J and Ferdinandy, P. (2003). Super- marathon race increases serum and urinary nitrotyrosine and carbonyl levels. Eur. J. Clin. Invest. 33(8): 726-730.

Rebar, A. H., MacWilliams, P. S., Feldman, B., Metzger, F., Pollock, R.,and Roche, J. 2001. A guide to hematology in dogs and cats. CRC Press.

Reimer, M. E., Johnston, S. A., Leib, M. S., Duncan, R. B., Reimer, D. C., Marini, M., and Gimbert, K. 1999. The gastroduodenal effects of buffered aspirin, carprofen, and etodolac in healthy dogs. J. Vet. Intern. Med. 13(5): 472-477.

Rippa, E., La Monica, G., Allocca, R., Romano, M. F., De Palma, M., and Arcari, P. 2011. Overexpression of gastrokine 1 in gastric cancer cells induces Fas- mediated apoptosis. .J ..Cell. Physio 226(10): 2571-2578.

Rodriguez, J. Y., Lewis, B. C., and Snowden, K. F. 2014s. Distribution and characterization of Heterobilharzia americana in dogs in Texas. Vet Parasitol. 203(1): 35-42.

Rodríguez-Franco, F., Sainz, A., Tesouro, M.A. and Amusategui, I. 1997. Gastritis crónicaantralasociada a duodenitisidiopáticacomocausa de vómitocrónico en el perro. Pequenos Animales, 10: 5-10.

Rohrer, C. R., Hill, R. C., Fischer, A., Fox, L. E., Schaer, M., Ginn, P. E. and Burrows, C. F. 1999. Gastric hemorrhage in dogs given high doses of 
methylprednisolone sodium succinate. Am. J. Vet. Res. 60(8): 977-981.

Rohss, K., Lind, T. and Wilder-Smith, C. 2004. Esomeprazole $40 \mathrm{mg}$ provides more effective intragastric acid control than lansoprazole $30 \mathrm{mg}$, omeprazole 20 $\mathrm{mg}$, pantoprazole $40 \mathrm{mg}$ and rabeprazole $20 \mathrm{mg}$ in patients with gastro-oesophageal reflux symptoms. Eur. J. Clin. Pharmacol. 60(8): 531-539.

Rugge, M., Correa, P., Dixon, M. F., Fiocca, R., Hattori, T., Lechago, J., and Watanabe, H. 2002. Gastric mucosal atrophy: interobserver consistency using new criteria for classification and grading. Aliment. Pharmacol. Ther. 6(7): 1249-1259.

Saravanan, M., Nagarajan, B., Kavitha, S., Balachandaran, C. and Srinivasan, S. R. 2012. Duodenoscopic appraisal of duodenal ulcer in dogs. Vet. World. $5(7)$.

Sass, B. 1970. Perforating gastric ulcer associated with lead poisoning in a dog. J. Am. Vet. Med. Assoc, 157(1): 76-78.

Sattasathuchana P. and Steiner J. M. 2014. Canine eosinophilic gastrointestinal disorders. Anim. Health Res. Rev., 15: 76-86.

Sawant, P., Das, H. S., Desai, N., Kalokhe, S., and Patil, S. 2004. Comparative evaluation of the efficacy and tolerability of itopride hydrochloride and domperidone in patients with nonulcer dyspepsia. JAPI, 52: 626-628.

Schulman, R. L. and Krawiec, D. R. 2000. Gastrointestinal complications of uremia. Kirks Current Veterinary Therapy. 13: 864-865.

Schulman, R. L. and Krawiec, D. R. 2000. Gastrointestinal complications of uremia. Kirks Current Veterinary Therapy. 13: 864-865.

Scott, L.J., Dunn,C. J., Mallarkey, G. and Sharpe, M. 2002. Esomeprazole. Drugs, 62(10): 1503-1538.
Shaheen, M., Zaman, A., and Muhee, A. 2010. Clinical, Endoscopic and Therapeutic Studies on Canine Gastritis. Intas Polivet, 11(2).

Sharman, M. J., Bacci, B., Santos, L., and Mansfield, C. S. 2017. Gastrokine mRNA expression in gastric tissue from dogs with helicobacter colonisation but without inflammatory change during treatment. Vet. Immunol. Immunopathol., 187: 28-34.

Shaw, N., Burrows, C. F., and King, R. R. 1997. Massive gastric hemorrhage induced by buffered aspirin in a greyhound. J. Am. Anim. Hosp. Assoc., 33(3): 215-219.

Simpson K, W. 2013. Stomach. In : Canine and Feline Gastroenterology, Washabau R. J., Day M. J., Eds, Elsevier saunders, St. Louis, 606-650.

Simpson, K., Neiger, R., DeNovo, R., and Sherding, R. 2000. The relationship of Helicobacter spp. infection to gastric disease in dogs and cats. J. Vet. Intern. Med., 14(2): 223-227.

Smith, J. A., Gray, A. B., Pyne, D. B., Baker, M. S., Telford, R. D., and Weidemann, M. J. 1996. Moderate exercise triggers both priming and activation of neutrophil subpopulations. Am. J. Physiol. Regul. Integr. Comp. Physiol., 270(4): R838-R845.

Smithuis, R. H., \& Op den Orth, J. O. 1989. Gastric fluid detected by sonography in fasting patients: relation to duodenal ulcer disease and gastric-outlet obstruction. Am. J. Roentgenol., 153(4): 731-733.

Sorjonen, D. C., Dillon, A. R., Powers, R. D. and Spano, J. S. 1983. Effects of dexamethasone and surgical hypotension on the stomach of dogs: clinical, endoscopic, and pathologic evaluations. Am. J. Vet. Res. 44(7): 1233-1237. 
Stanton, M. E., and Bright, R. M. 1989. Gastroduodenal ulceration in dogs. J. Vet. Intern. Med., 3(4): 238-244..

Suchodolski, J. S., Steiner, J. M., Ruaux, C. G., and Williams, D. A. 2003. Serum concentrations of pepsinogen $\mathrm{A}$ in healthy dogs after food deprivation and after feeding. Am. J. Vet. Res., 64(9): 1146-1150.

Suchodolski, J. S., Steiner, J. M., Ruaux, C. G., Boari, A., and Williams, D. A. 2002. Purification and partial characterization of canine pepsinogen A and B. Am. J. Vet. Res., 63(11): 1585-1590.

Sullivan, M., and Yool, D. A. 1998. Gastric disease in the dog and cat. Vet. J., 156(2): 91-106.

Sutton, D., Vinberg, C., Gustafsson, A., Pearce, J., and Greenwood, N. 2013. Canine parvovirus type $2 \mathrm{c}$ identified from an outbreak of severe gastroenteritis in a litter in Sweden. Acta Vet. Scand., 55(1): 64.

Taggart, R. T., and Samloff, I. M. 1987. Immunochemical, electrophoretic, and genetic heterogeneity of pepsinogen I: characterization with monoclonal antibodies. Gastroenterol., 92(1): 143150

Talbert, A., Thuo, N., Karisa, J., Chesaro, C., Ohuma, E., Ignas, J., and Maitland, K. 2012. Diarrhoea complicating severe acute malnutrition in Kenyan children: a prospective descriptive study of risk factors and outcome. PloS one, 7(6): e38321.

Tolbert, K., Bissett, S., King, A., Davidson, G., Papich, M., Peters, E., and Degernes, L. 2011. Efficacy of oral famotidine and 2 omeprazole formulations for the control of intragastric $\mathrm{pH}$ in dogs. J. Vet. Intern. Med., 25(1): 47-54.

Tomoda, T., Takeda, K., Kurashige, T., Enzan, H., \& Miyahara, M. 1994. Acetylsalicylate (ASA)- induced mitochondrial dysfunction and its potentiation by $\mathrm{Ca} 2+$. Liver Int., 14(2): 103-108.

Tomooka, Y., Onitsuka, H., Goya, T., Koga, T., Uchida, S., Russell, W. J., \& Torisu, M. 1989. Ultrasonography of benign gastric ulcers. Characteristic features and sequential follow- ups. J. Ultrasound Med., 8(9):513-517.

Tsendsuren, T., Jun, S. M., \& Mian, X. H. 2006. Usefulness of endoscopic ultrasonography in preoperative TNM staging of gastric cancer. World J. Gastroenterol., 12(1): 43.

Tsunada, S., Iwakiri, R., Noda, T., Fujimoto, K., Fuseler, J., Rhoads, C. A., and Aw, T. Y. 2003. Chronic exposure to subtoxic levels of peroxidized lipids suppresses mucosal cell turnover in rat small intestine and reversal by glutathione. Dig. Dis. Sci., 48(1): 210222.

Ulutas, P. A., Bayramli, G., Ulutas, B., Kiral, F., \& Atasoy, A. 2006. Oxidative stress and non-enzymatic antioxidant status in dogs with aspirin induced gastric mucosal injury. Rev. Med. Vet., 157(8/9): 401.

Vaananen, H., Vauhkonen, M., Helske, T., Kaariainen, I., Rasmussen, M., TunturiHihnala, H. and Ristikankare, M. 2003. Non-endoscopic diagnosis of atrophic gastritis with a blood test. Correlation between gastric histology and serum levels of Gastrin- 17-17 and pepsinogen I: a multicentre study. Eur. J. Gastroenterol. Hepatol., 15(8): 885-891.

Valin, I., \& Allard, F. 2012. Ulcère perforant de l'estomac chez un retriever du Labrador. Pratique Médicale et Chirurgicale de l'Animal de Compagnie, 47(1): 23-29.

Van der Gaag, I., van Niel, M. H., Belshaw, B. E., \& Wolvekamp, W. T. C. 1991. Gastric granulomatous cryptococcosis 
mimicking gastric carcinoma in a dog. Vet. Q., 13(4): 185-190.

Van der Merwe, L. L., Kirberger, R. M., Clift, S., Williams, M., Keller, N., \& Naidoo, V. 2008. Spirocerca lupi infection in the dog: a review. Vet. J., 176(3): 294-309.

Vaughn, D. P., Syrcle, J., and Cooley, J. 2014. Canine giant hypertrophic gastritis treated successfully with partial gastrectomy. J. Am. Anim. Hosp. Assoc., 50(1): 62-66.

Waldrop, J. E., Rozanski, E. A., Freeman, L. M., and Rush, J. E. 2003. Packed red blood cell transfusions in dogs with gastrointestinal hemorrhage: 55 cases (1999-2001). J. Am. Anim. Hosp. Assoc., 39(6): 523-527..

Wallace, J. L., and Ma, L. 2001. Inflammatory mediators in gastrointestinal defense and injury. Exp. Biol. Med., 226(11): 1003-1015.

Wallace, M. S., Zawie, D. A., and Garvey, M. S. 1990. Gastric ulceration in the dog secondary to the use of nonsteroidal antiinflammatory drugs. J. Am. Anim. Hosp. Assoc., 26(5): 467-472.

Webb, C. and Twedt, D. C. 2003. Canine gastritis. Veterinary Clinics of North America: Small Anim. Pract., 33(5): 969-985.

Wiinberg, B., Spohr, A., Dietz, H. H., Egelund, T., Greiter- Wilke, A., McDonough, S. P. and Simpson, K. W. 2005. Quantitative analysis of inflammatory and immune responses in dogs with gastritis and their relationship to Helicobacter spp. infection. J. Vet. Intern. Med., 19(1): 4-14.

Wilcock B. 2013. Histopathology. In: Canine and Feline Gastroenterology, RJ Washabau, MJ Day, Eds., Elsevier Saunders, St. Louis, 333-385.

Wilder- Smith, C. H., Rohss, K., Bondarov, P., Hallerback, B., Svedberg, L. E. and Ahlbom, H. 2004. Esomeprazole 40 mg $\mathrm{i} / \mathrm{v}$ provides faster and more effective intragastric acid control than pantoprazole $40 \mathrm{mg} \mathrm{i} / \mathrm{v}$ : results of a randomized study. Aliment. Pharmacol. and Ther., 20(10): 1099-1104.

Xing, R., Li, W., Cui, J., Zhang, J., Kang, B., Wang, Y., and Lu, Y. 2012. Gastrokine 1 induces senescence through $\mathrm{p} 16 / \mathrm{Rb}$ pathway activation in gastric cancer cells. Gut, 61(1): 43-52.

Yoon, J. H., La Cho, M., Choi, Y. J., Back, J. Y., Park, M. K., Lee, S. W., and Lee, J. Y. 2013. Gastrokine 1 regulates NF- $\kappa B$ signaling pathway and cytokine expression in gastric cancers. J. Cell. Biochem., 114(8): 1800-1809.

Yoshida, Y., Singh, I., \& Darby, C. P. 1992. Effect of salicylic acid and calcium on mitochondrial functions. .Acta Neurol ..Scand, 85(3): 191-196.

Zamocky M., Furtmüller P.G. and Obinger C. 2008. Evolution of catalases from bacteria to humans. Antioxid. Redox Signal., 10(9): 1527-1547.

\section{How to cite this article:}

Pankaj Kumar Patel, Sawita Kumari Patel S.K. Dixit and Rathore, R.S. 2018. Gastritis and Peptic Ulcer Diseases in Dogs: A Review. Int.J.Curr.Microbiol.App.Sci. 7(03): 2475-2501. doi: https://doi.org/10.20546/ijcmas.2018.703.288 